\title{
The effect of computerized decision support systems on cardiovascular risk factors: a systematic review and meta-analysis
}

\author{
T. Katrien J. Groenhof ${ }^{*}$ (D), Folkert W. Asselbergs ${ }^{2,3,4}$, Rolf H. H. Groenwold ${ }^{5,6}$, Diederick E. Grobbee ${ }^{1}$, \\ Frank L. J. Visseren ${ }^{7}$, Michiel L. Bots ${ }^{1}$ and on behalf of the UCC-SMART study group
}

\begin{abstract}
Background: Cardiovascular risk management (CVRM) is notoriously difficult because of multi-morbidity and the different phenotypes and severities of cardiovascular disease. Computerized decision support systems (CDSS) enable the clinician to integrate the latest scientific evidence and patient information into tailored strategies. The effect on cardiovascular risk factor management is yet to be confirmed.

Methods: We performed a systematic review and meta-analysis evaluating the effects of CDSS on CVRM, defined as the change in absolute values and attainment of treatment goals of systolic blood pressure (SBP), low density lipoprotein cholesterol (LDL-c) and HbA1c. Also, CDSS characteristics related to more effective CVRM were identified. Eligible articles were methodologically appraised using the Cochrane risk of bias tool. We calculated mean differences, relative risks, and if appropriate $\left(1^{2}<70 \%\right)$, pooled the results using a random-effects model.

Results: Of the 14,335 studies identified, 22 were included. Four studies reported on SBP, 3 on LDL-C, 10 on CVRM in patients with type II diabetes and 5 on guideline adherence. The CDSSs varied considerably in technical performance and content. Heterogeneity of results was such that quantitative pooling was often not appropriate. Among CVRM patients, the results tended towards a beneficial effect of CDSS, but only LDL-c target attainment in diabetes patients reached statistical significance. Prompting, integration into the electronical health record, patient empowerment, and medication support were related to more effective CVRM.

Conclusion: We did not find a clear clinical benefit from CDSS in cardiovascular risk factor levels and target attainment. Some features of CDSS seem more promising than others. However, the variability in CDSS characteristics and heterogeneity of the results - emphasizing the immaturity of this research area - limit stronger conclusions. Clinical relevance of CDSS in CVRM might additionally be sought in the improvement of shared decision making and patient empowerment.
\end{abstract}

Keywords: CDSS, Computerized decision support, Cardiovascular risk management

\section{Background}

The fast paced nature of medical science and practice challenge physicians to keep practicing concurrent to guidelines and the latest evidence. Some state that health care decision making has never been more complex because of multi morbidity and different severities of

\footnotetext{
* Correspondence: t.k.j.groenhof@umcutrecht.nl

${ }^{1}$ Julius Center for Health Sciences and Primary Care, University Medical Center Utrecht, University of Utrecht, Heidelberglaan 100, 3584, CX, Utrecht, the Netherlands

Full list of author information is available at the end of the article
}

disease clustered in one individual [1]. Cardiovascular risk management (CVRM) in high-risk patients asks for a comprehensive approach and a lifelong effort of patients that affects lifestyle and dictates adherence to medical treatment of risk factors. CVRM is complex, because it involves a large number of risk factors that may change over time. CVRM guidelines provide support and advocate the use of risk prediction algorithms for the identification of patients at risk for (recurrent) cardiovascular events [2]. Treatment decisions, such as starting or intensifying lipid blood pressure lowering treatment are based

(c) The Author(s). 2019 Open Access This article is distributed under the terms of the Creative Commons Attribution 4.0 International License (http://creativecommons.org/licenses/by/4.0/), which permits unrestricted use, distribution, and reproduction in any medium, provided you give appropriate credit to the original author(s) and the source, provide a link to the Creative Commons license, and indicate if changes were made. The Creative Commons Public Domain Dedication waiver (http://creativecommons.org/publicdomain/zero/1.0/) applies to the data made available in this article, unless otherwise stated. 
on estimated absolute cardiovascular risk in individual patients and their absolute levels of risk factors. Yet, there seems to be a gap between guideline recommendations and daily clinical practice [3]. Adherence to guidelines varies between medical disciplines and between treating physicians, even for similar patients [3]. Completeness of risk factor assessment, pharmacological and non-pharmacological treatment initiation and long term uptake of treatment in patients with a cardiovascular condition can be further optimized, which potentially leads to reduction in to preventable cardiovascular morbidity and mortality $[4,5]$.

Computerized decision support systems (CDSS) are digital information systems that typically show a summary of patient data in an app, on a webpage, or within the electronic health record (EHR). In CVRM, CDSS can be used for reminders for assessment of risk factor levels, comprehensive presentation and evaluation of risk factor levels and cardiovascular risk estimates and for recommendation of evidence-based treatment modalities. This way, patient data and scientific evidence are incorporated into tailored strategies in daily practice [6]. CDSS have the potential to improve shared decision making, treatment adherence and eventually health outcome, without additional utilization of health-care resources [7].

Multiple apps and decision support systems have been and are being developed: over the last years, at least 16 systematic and 2 narrative reviews on the effectiveness of CDSS on practitioner performance and patient outcomes have been published [8-25]. But due to the large variation in CDSS functionalities - drug alerts, laboratory test ordering, treatment advice - clinical applications, and patient populations these reviews are restricted in terms of generalizability and applicability. Cardiovascular disease prevention is a multidisciplinary process in a population characterized by multimorbidity and multiple diseases of different severities. Preferably, a CDSS focused on CVRM should fit all these patients. Recently, Njie et al. reported a systematic review on CDSS in cardiovascular risk management, focusing on improvement in guideline adherence by physicians [26]. Complete assessment of vascular risk factors and guideline-adherent clinical testing increased) [26]. It would be even more clinically relevant to know whether use of CDSS would improve cardiovascular risk factor levels and ultimately reduce cardiovascular event rates. This is yet to be investigated.

This systematic review of randomized clinical trials evaluates the effects of CDSS on CVRM and aims to identify CDSS characteristics that are related to effective CVRM.

\section{Methods}

This review was performed in accordance with the Preferred Reporting Items for Systematic Reviews (PRISMA) guidelines [27].

\section{Outcomes of interest}

The primary focus of the systematic review was on absolute difference in and target attainment of blood pressure, LDL-c and HbA1c. The secondary focus was on the evidence based medicine practice performance of the user, defined as actions compliant to the guidelines applied in the specific studies. Lastly we investigated whether the technical embedding, the measurements provided, the level of evidence provided, the level of therapy advice provided and prompting were related to the likelihood of having positive, beneficial results.

\section{Study eligibility}

Randomized controlled trials (RCT's) and cluster RCT's using CDSS as an intervention on CVRM were included. As parameters for CVRM the established, objectively measurable and pharmacological treatable risk factors were used: elevated blood pressure, impaired glycemic control and dyslipidemia. Although relevant in CVRM, effects on lifestyle factors such as smoking and physical inactivity were outside the scope of this review.

Studies were included if the CDSS was used for a patient specific advice given to the physician or about to make a treatment decision for the individual patient (not the group-effect). Studies on medical training or primary users other than physicians were excluded. Assessments of diagnostic or prognostic CDSS tools compared with routine care were excluded. Advice on prescription of medicine supported by CDSS was included, but drug prescribing error alarm systems were not. Clinical support using out-of-date systems (fax, paper flowcharts etc.) or trials focusing on implementation of an EHR were excluded.

\section{Search strategy}

A systematic literature search was conducted in PubMed, Embase and Cochrane Library for publications up to March 20th 2018. A combination synonyms of "computerized decision support systems" AND ("system performance" OR "hypertension" OR "dyslipidemia" OR "diabetes") AND "randomized controlled trial" and synonyms was used. The detailed search strategy is in Additional file 1.

Data collection and assessment of methodological quality A data collection form was designed prior to screening of the retrieved articles. KG subtracted the data from the retrieved articles. Uncertainties were resolved by discussion with an objective expert (Prof. Dr. R. Scholten). Additional quality assessment was performed using the Cochrane Collaboration's tool to assess the risk of bias [28]. Blinding of participants and physicians was not possible due to the nature of the intervention. Therefore we excluded this criterion from the appraisal. All studies 
were scored on the randomization process, blinding of outcome assessment, attrition bias, reporting bias and other potential sources of bias. Additionally, cluster RCT'S were assessed on recruitment bias, baseline imbalance, loss of clusters, adjustments for clustering in the analysis and comparability with individually randomized trials. Items were scored low risk of bias, unknown risk of bias or high risk of bias. Studies with more than two items at 'a high risk of bias' were excluded from further analyses.

Data processing and additional analyses were performed in RevMan [29]. For continuous outcomes, we calculated the mean differences (MDs) with 95\% confidence intervals (CI's) between CDSS and usual care at follow up. For dichotomous outcomes, we calculated the relative risks with 95\% CI's between CDSS and usual care at follow up. If standard deviations were missing, we calculated them using reported CIs, standard errors, $\mathrm{t}$ and/or $p$ values, according to the principles provided in the Cochrane handbook [30]. We assessed heterogeneity using the $\mathrm{I}^{2}$ [31]. Results were considered too heterogeneous for reliable pooling if the $\mathrm{I}^{2}$ was $>70 \%$ [32]. Where appropriate, results were pooled using a random-effects model.

\section{Results}

The systematic literature search (Additional file 1) yielded 14,335 unique articles. Figure 1 shows the number of articles that were retrieved from the searches, were reviewed and were included in the analysis. After selection based on title and abstract, 53 articles were considered potentially eligible for answering the research question. Full text screening followed. Three studies were excluded because of the study design: one study performed a retrospective cross sectional study [33], two studies performed a before and after study [34, 35]. Dorr et al. did not focus solely on CVRM interventions [36] and was excluded. Four studies featured interventions focusing on influencing patient behaviour [37], learning strategies [38], data search queries [39] or prediction models [40] that were non-compatible with our intervention of choice, and were excluded. Three articles focused on patient and physician satisfaction and/or CDSS uptake rather than measurable clinical outcomes and were excluded [41-43]. Ten studies did not answer our research question [44-52]. Three studies featured an out-of-date system, three focused on the implementation of an EHR [53-59]. Lipton et al. investigated glucose control at the intensive care unit, which was considered a too different population [60]. Also a study on a continuous monitoring system was excluded from further assessments [61]. That left us with 25 studies that were critically appraised.

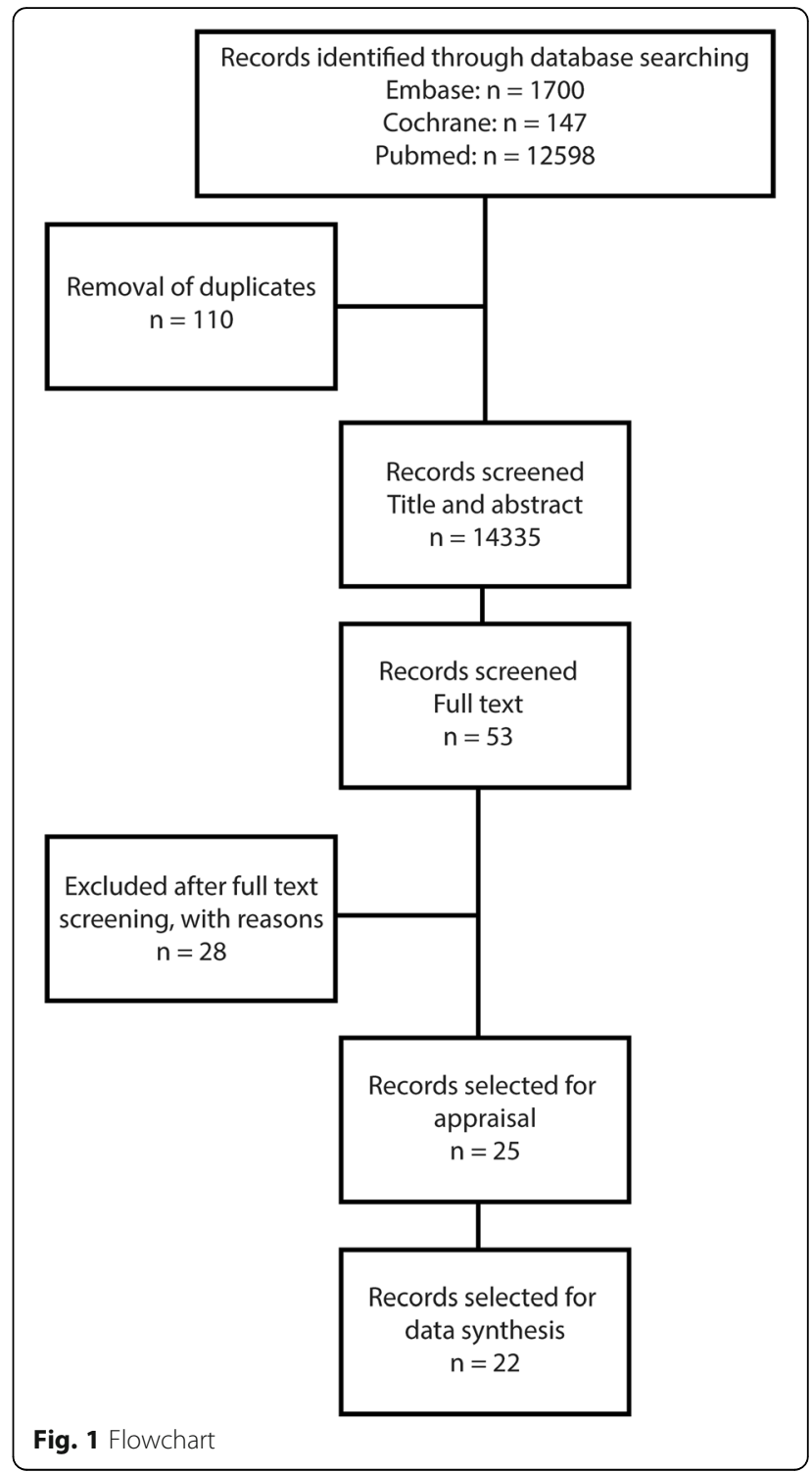

\section{Critical appraisal}

Randomization process was not sufficiently reported by two studies [62,63] (Additional file 2. Critical appraisal table). Two studies reported considerable (up to $>20 \%$ ) loss to follow up [62, 64]. Furthermore insufficient information was provided on the prevention of (selection and detection) bias by Saenz et al. [63] That left us with 17 articles on risk factor changes (Table 1) proceeded to data analysis and 5 articles providing evidence on guideline adherence.

\section{CVRM on elevated blood pressure}

A total of 4 studies investigated blood pressure and blood pressure target attainment in CVRM patients (Table 1), of which 3 looked at mean blood pressure (Fig. 2.1) $[65,67,68]$ and 3 at target attainment (Fig. 2.2) $[65,66,68]$. The studies were performed in primary 


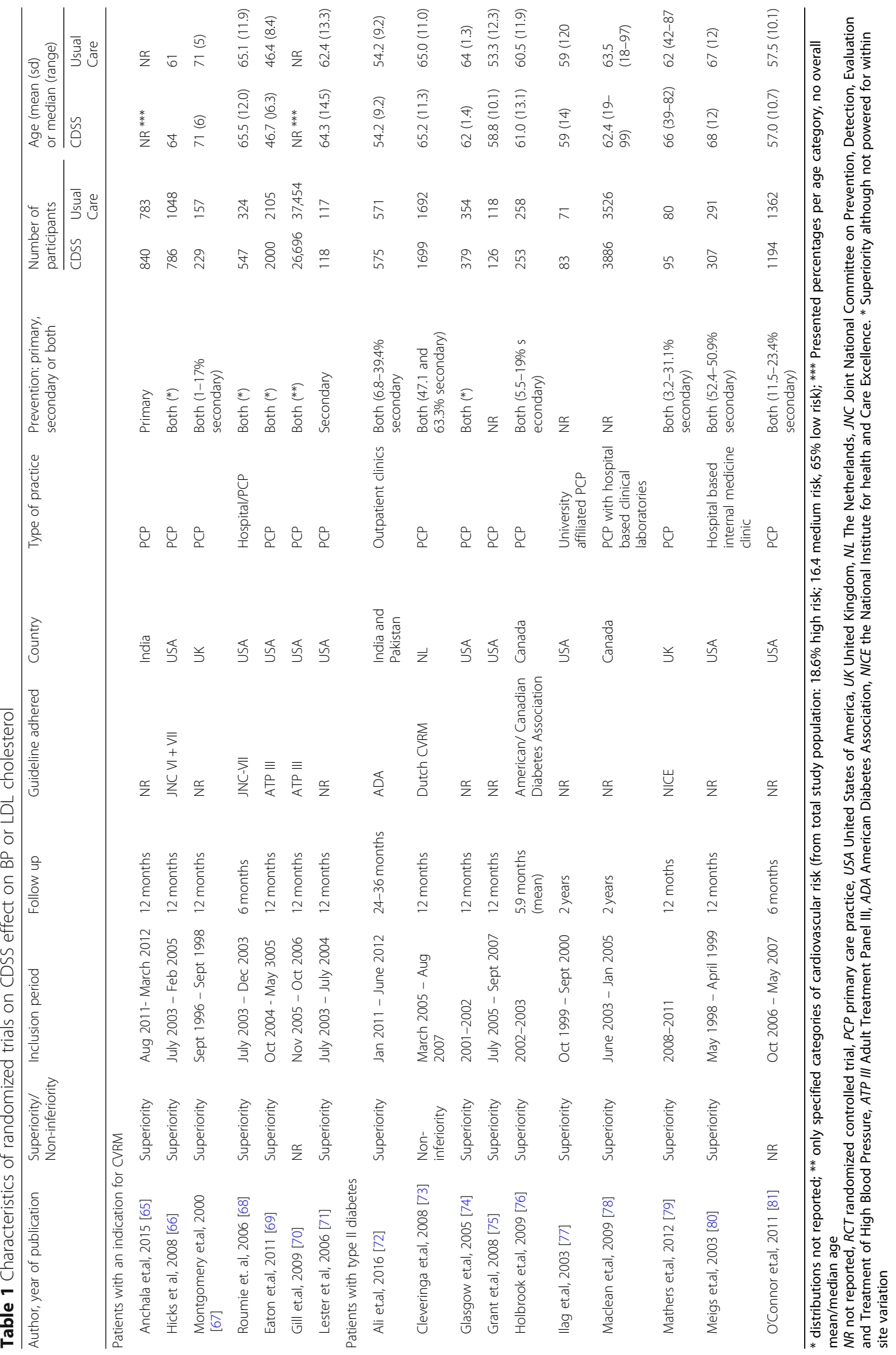




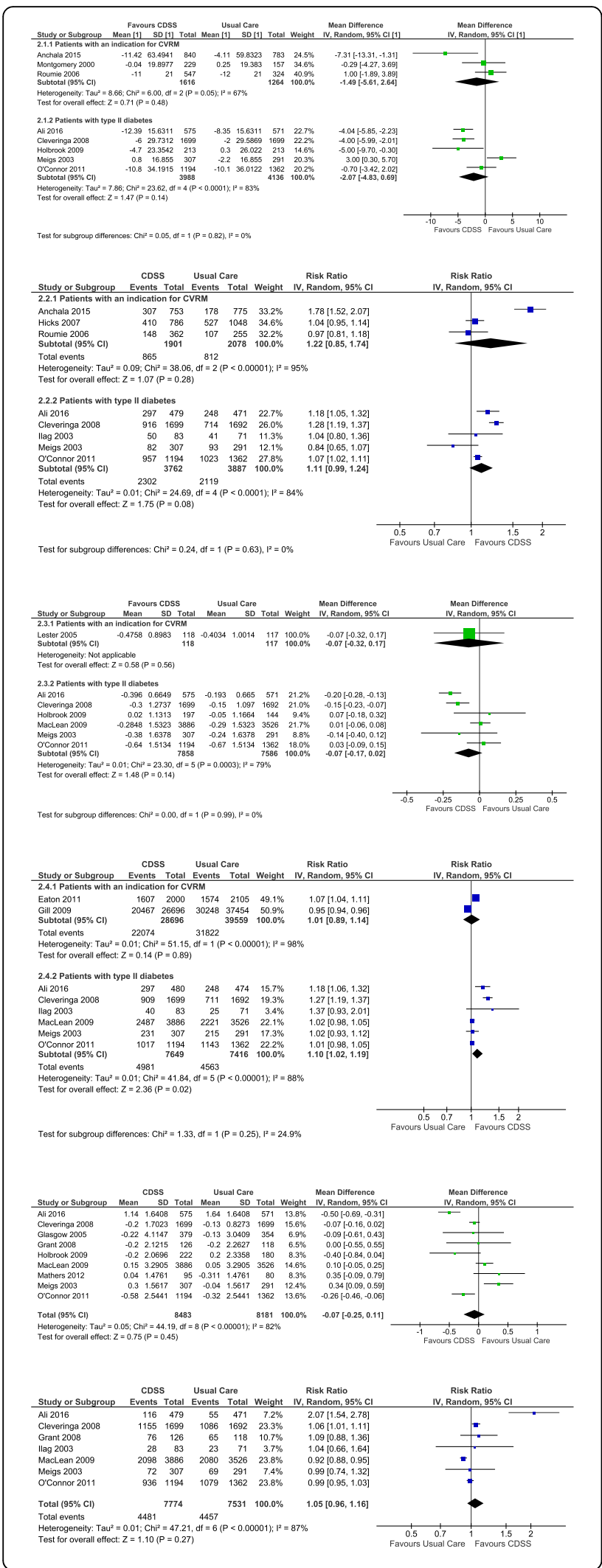

Fig. 2 2.1 Absolute change of mean systolic blood pressure $(\mathrm{mmHg})$ at follow up in CDSS and usual care. 2.2 Prevalence of blood pressure target attainment at follow up in CDSS and usual care. 2.3 Absolute change of $L D L-c$ change $(\mathrm{mmol} / \mathrm{L})$ at follow up in CDSS and usual care. 2.4 Prevalence of LDL-c target attainment at follow up in CDSS and usual care. 2.5 Absolute change in mean $\mathrm{HbA} 1 \mathrm{c}$ in patients with type II diabetes $(\mathrm{mmol} / \mathrm{mol})$. 2.6 Prevalence of HbA1c target attainment in patients with type II diabetes at follow up in CDSS and usual care

care practices, mostly with a follow up of 12 months. The CDSS was integrated in the electronical health record in 3 studies [65-67]. All CDSS provided a risk factor overview, only 2 a cardiovascular risk score $[65,67]$. Prompting occurred in 3 studies $[65,66,68]$.

In the studies on absolute change in mean blood pressure, 1594 patients received CDSS care and 1237 usual care. The mean blood pressure decreased more in those with CDSS care compared to usual care in 2 out of 3 studies. The overall pooled mean difference in systolic pressure was $-1.49 \mathrm{mmHg}(95 \% \mathrm{CI}-5.861 ; 2.63)$, but heterogeneity of results $\left(\mathrm{I}^{2}=67 \%\right)$ is only just below the maximum $\mathrm{I}^{2}$ for a reliable meta-analysis $[65,66,68]$.

In the studies on target attainment, 1901 patients received CDSS care and 2078 usual care. The number of patients reaching their blood pressure goal was higher with CDSS care than with usual care (pooled risk ratio [RR] $1.22(95 \% \mathrm{CI} 0.85 ; 1.74)$, but the heterogeneity of results $\left(\mathrm{I}^{2}=95 \%\right)$ was too large to perform a reliable meta-analysis $[65,67,68]$.

A total of 7 studies investigated blood pressure and blood pressure target attainment in patients with type II diabetes (Table 1), of which 6 studies investigated mean blood pressure $[72,73,76,80,81]$ and 5 investigated target attainment $[72,73,77,80,81]$. The studies were performed in primary care practices, mostly with a follow up was 12 months. The CDSS was integrated in the electronical health record in 4 studies. All CDSS provided a risk factor overview, none a cardiovascular risk score. Prompting occurred in 1 study [72].

The overall pooled mean difference in systolic pressure and difference in number of patients reaching their blood pressure goal was comparable to the CVRM population: studies were relatively more positive towards CDSS care, but the heterogeneity of results $\left(\mathrm{I}^{2}>83 \%\right)$ was too large to perform a reliable meta-analysis.

\section{CVRM on dyslipidemia}

A total of 3 studies investigated lipid control in CVRM patients (Table 1), of which 1 study investigated mean LDL-c [71] and 2 investigated LDL-c target attainment [69, 70]. The studies were conducted in primary care practices with a follow up of 12 months [69-71].The CDSS was built within the electronical health record in two studies [70, 71]. 
Eaton et al. used a PDA based system and integrated patient support into the program [69]. All CDSS provided a risk factor overview, target support and medication support. None of the CDSSs' featured a cardiovascular risk score. Prompting occurred in two studies [70, 71].

Only one study reported on change in mean LDL-c (slightly lower after CDSS $(-0.48(0.08) \mathrm{mmol} / \mathrm{L})$ than after usual care (- $0.41(0.09) \mathrm{mmol} / \mathrm{L}$; Fig. 2.3) [71]. The studies on target attainment showed contradictory results. On average, there was no difference between CDSS and usual care groups (RR 1.01 (95\%CI 0.89; 1.14), I $\left.\mathrm{I}^{2} 98 \%\right)[69,70]$.

A total of 6 studies investigated lipid control in patients with type II diabetes (Table 1), of which 5 studies investigated mean LDL-c $[73,76,78,80,81]$ and 5 investigated LDL-c target attainment [72, 73, 77, 78, 80, 81].

The 6 studies targeting cholesterol performed in patients with type II diabetes (7858 CDSS, 7586 usual care) showed widely variable results for mean LDL-c change ( $\mathrm{I}^{2} 79 \%$, Fig. 2.3.1). A borderline statistically significant improvement of attained LDL targets was found in CDSS care compared to usual care (pooled RR 1.10(95\% CI 1.02; 1.09), I² 88\%; Fig. 2.4.1).

\section{CVRM on glycemic control in diabetics}

A total of 10 studies investigated glycemic control in patients with type II diabetes (Table 1), of which 9 studies investigated mean HbA1c [72-76, 78-81] and 7 investigated HbA1c target attainment [72, 73, 75, 77, 78, 80, 81]. Cleveringa et al. was the only study with a non-inferiority design [73]. Most studies were conducted in primary care practices and the follow up ranged from 6 months to 2 years. As far as described, three studies were EHR based $[75,77,80]$, two web-applications [72, 76], one personal digital assistant (PDA)/tablet [79], 1 CD-rom [74] and one system using the EHR to extract data but using fax for promoting [78]. All studies provided a risk factor overview but none a cardiovascular risk score. Furthermore, two included patient motivating techniques into the intervention [75, 76]. Additionally, four studies organized a guideline instruction session [72, 73, 79, 81].

In the studies on absolute change in mean HbA1c, 8483 patients received CDSS care and 8181 usual care. The mean HbA1c seems to decrease more after CDSS care than after usual care (MD -0.07\% (95\% CI -0.25;-0.11\%), I ${ }^{2}$ 82\%; Fig. 2.5) [72-76, 78-81]. Similar prevalence HbA1c target attainment (CDSS $n=7774$, usual care $n=7531$ ) was found in care supported by CDSS and usual care (RR 1.05 (95\%CI 0.96; 1.16); Fig. 2.6) [72, 73, 75, 77, 78, 80, 81]. There was insufficient homogeneity to reliably conduct pooled analysis $\left(\mathrm{I}^{2} 87 \%\right)$.

\section{Usual care characteristics}

Detailed description of usual care was lacking in 20 of the 24 reports. Roumie et al. sent all participants an e-mail message that explained the planned intervention and provided physician education in all groups [68]. Similarly, a poster with a CVRM flowchart including which risk factors to assess, classification of risk instructions and advice for lifestyle interventions was provided to the usual care group in another study [65]. A patient activation tool was provided via a PDA with smoking cessation, weight loss, healthy diets, exercise and lipid lowering medication adherence materials and web access to calculate the heart-age in the study of Eaton et al. [69]. Grant et al. provided their controls with a questionnaire on family history and health maintenance journals [75].

\section{CDSS characteristics}

Apart from the technical performance of CDSS, design and usability are important drivers behind the success of the systems. The interaction design can influence error through the length and proximity of selection items, bullet points and similar item descriptions [82]. A study on design characteristics showed that information should be displayed all at once and at one glance [83].

The CDSS characteristics of the studies included in this analysis are listed in Table 2. The cardiovascular risk score was only provided by two of the studies on blood pressure care, not in patients with type II diabetes [65, 67]. Advice on specific medication (name and dose) was not unanimously associated with improvement of the health outcomes $[65,66,69,70,71,75,77,79$, 80]. Prompting of measurements and treatment strategies were associated with positive CDSS results in five out of seven studies [66, 68, 70-72, 78, 84]. Studies using prompting that were not associated with positive results used a web-link (not EHR) based [68] and fax reminders [78]. Almost all studies in patients with type II diabetes include patient activation in the CDSS intervention. The lack of insight into the automated computation and the source of information decreased user satisfaction $[85,86]$. CDSS built in within the EHR were superior to usual care in seven out of nine studies. Non-EHR based systems CDSS were superior to usual care in three out of eight studies.

\section{Guideline adherence}

Five RCT's reported on general improvement of adherence to guidelines in patients with an indication for CVRM, with and without diabetes and/or a history of a cardiovascular event (Table 3) [87-91].

The CARDSS (cardiac rehabilitation decision support system) was implemented in 21 centers (including 2878 patients), focusing on exercise, education, relaxation and lifestyle change after a cardiac event. CDSS increased concordance with guideline recommended interventions by $3.5 \%$ (95\%CI 0.1; 5.2\%). Furthermore, CDSS significantly 


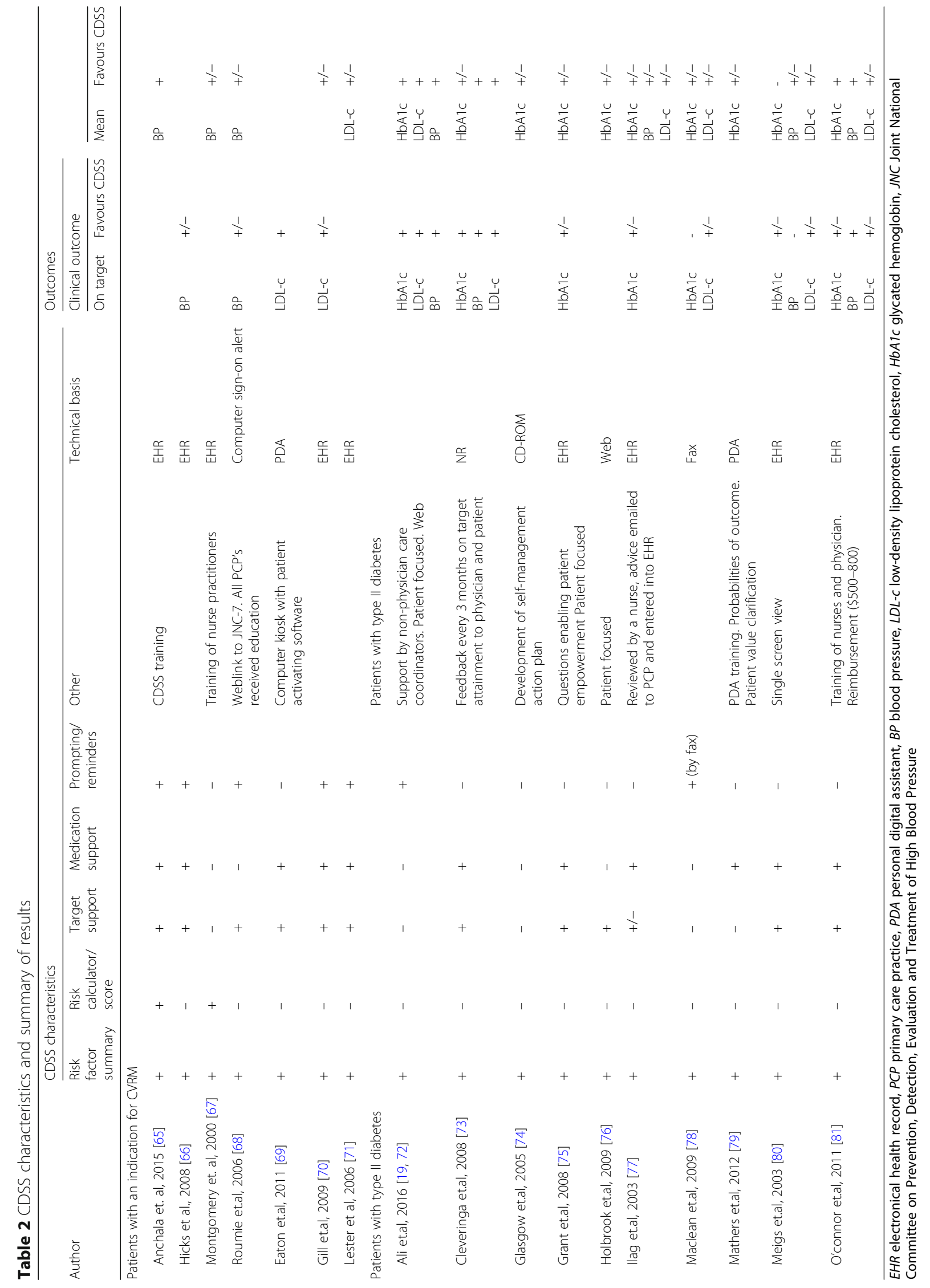


reduced both overtreatment (25.7\% (95\%CI 4.3; 54.1\%)) and under treatment (42.8\% (95\%CI 1.1; 68.0\%)) [87].

The COMPETE III (Computerization of Medical Practices for the Enhancement of Therapeutic Effectiveness) study assessed electronic vascular risk decision support in patients with increased risk or a history of a cardiovascular disease. The CDSS improved a composite process outcome with 4.70 points on a 27 point scale $((95 \%$ CI $3.63 ; 5.71) p<0.001)$. The CDSS group reported a higher improvement of the continuum of care (odds ratio (OR) $4.18(95 \% \mathrm{CI} 3.04 ; 5.76), p<0.001)$ and their ability to improve their health (OR 3.07 (95\%CI 2.37; 3.99) $p<0.01)$ [88]. In patients with diabetes without and with a history of acute myocardial infarction $(n=3956)$ and stroke $(n=2158)$, more antiplatelet drugs $(+2.7 \%$ vs $+0.15 \% ; p<0.001)$ and lipid lowering drugs $(+4.2 \%$ vs. $+2.8 \%, p=0.001)$ were prescribed in the CDSS group [89]. Another study amongst patients with diabetes $(n=4549)$ and coronary artery disease (CAD, $n=2199$ ) also showed an improvement of diabetes care (OR 1.30 95\%CI 1.01; 1.67) and coronary heart disease risk management (OR 1.25 (95\%CI 1.01, 1.55)) amongst the CDSS patients [91]. Lastly, in a study in $>7000$ patients in primary care showed an increase in the number of deficiencies addressed amongst patients with diabetes or CAD (CDSS $11.4 \%$ vs. normal care $10.1 \%$ (OR 1.14 (95\%CI 1.02, 1.28), $p=0.01$ ) [90].

\section{Discussion}

A systematic review and meta-analysis was conducted to provide insight into the effects of computerized decision support systems (CDSS) on cardiovascular risk factor levels and identify characteristics of CDSS related to improved care. A considerable number of CDSS for CVRM were developed, but a clear clinical benefit is absent. Some features of CDSS seem more promising than others. However, the variability in approaches of CDSS and heterogeneity of the results limit stronger conclusions.
Due to differences in technical basis, content and comparison group, comparability of the studies included in this review is limited. CDSS vary greatly in technical approaches, as well as to how and to which extent they support the physician. In addition, or as a result, there was large heterogeneity in the results of the studies, such that definite conclusions cannot be drawn from the pooling of findings. Moreover, the usual care group was ill defined such that it was impossible to understand what care was delivered as standard. Visual inspection of funnel plots investigating the relationship between effect and sample size does not show a distinct publication bias (Additional file 3). But it is still possible that positive results on CDSS are more likely to get published. These aspects limit strong recommendations on success factors in use of CDSS. Also, our analyses were restricted by what was reported: some studies reported raw means, prevalence or odds ratios, others reported adjusted and/ or imputed effect measures [72, 76, 78, 84]. We were unable to incorporate these differences into our analyses. An easy, but major step forward would be to apply the existing guidelines for reporting trial results using drug or devices in the publications and registration in national or international trial registries.

Although very relevant in CVRM, effects on lifestyle factors such as smoking and physical inactivity were outside the scope of this review. CDSS focus on guideline adherent management measured by change in pharmacological treatment and risk factor profiles without registering meta-information on the decisions: how did the CDSS affect counselling by the physician and the shared decision making process? Helping the physician remember to address smoking can be achieved by CDSS, but hów to address this has proven to be an important factor in the uptake [92]. Lifestyle interventions in particular need a more personal approach that is directed towards coaching and long-term engagement, rather than incidental support of guideline adherent management (the goal of CDSS). Current literature is very positive about

Table 3 Study characteristics for studies on guideline adherence

\begin{tabular}{|c|c|c|c|c|c|c|}
\hline Author & $\begin{array}{l}\text { Superiority/ Non- } \\
\text { inferiority }\end{array}$ & Inclusion period & Follow up & Guideline adhered & Country & Type of practice \\
\hline $\begin{array}{l}\text { Goud et.al, } \\
2009 \text { [87] }\end{array}$ & Superiority & Jan 2005 - Dec 2005 & 12 months & $\begin{array}{l}\text { Cardiac } \\
\text { rehabilitation }\end{array}$ & $\begin{array}{l}\text { The } \\
\text { Netherlands }\end{array}$ & $\begin{array}{l}\text { Rehabilitation } \\
\text { center }\end{array}$ \\
\hline $\begin{array}{l}\text { Holbrook et.al, } \\
2011 \text { [88] }\end{array}$ & NR & April 2003-June 2005 & 12 months & NR & Canada & PCP \\
\hline $\begin{array}{l}\text { Mazzaglia et.al, } \\
2016 \text { [89] }\end{array}$ & Superiority & NR & 12 months & ESC & Italy & PCP \\
\hline $\begin{array}{l}\text { Schnipper et.al, } \\
2010 \text { [90] }\end{array}$ & NR & March 2007 - Aug 2007 & 30 days & NR & USA & PCP \\
\hline $\begin{array}{l}\text { Sequist et.al, } \\
2005 \text { [91] }\end{array}$ & NR & Oct 2002 - April 2003 & 6 months & ADA/AHA & USA & PCP \\
\hline
\end{tabular}

$N R$ not reported, $R C T$ randomized controlled trial, $P C P$ primary care practice, USA United States of America, $L$ low risk of bias, $U$ unknown risk of bias, $H$ high risk of bias, ESC European Society of Cardiology, AHA American Heart Association, ADA American Diabetes Association 
such smoking cessation interventions: there is consistent evidence that web-based and mHealth smoking cessation interventions may increase abstinence moderately [92].

Though the results are conflicting and strength of conclusions is limited, the findings from this study can perhaps be used to give direction to future developments. More evidence is needed on long-term evaluations including assessment of the effect on treatment adherence and vascular event rate [93]. This could the also include other relevant cardiovascular risks such as anti-coagulation therapy for patients with atrial fibrillation to prevent stroke, cardio protective medicine in heart failure patients to prevent death or cardiac function replacement therapy, and fluid balance in patients witch chronic kidney disease to prevent renal replacement therapy. The paucity of good quality studies, with sufficient sample size and follow up, on clinical outcomes hinders interpretation and restricts transposing these results into clinical practice. This again emphasizes that guidance for generating relevant evidence needs to be followed and taken up as requirement for funding and publication of novel developments [94]. In designing a study investigating the effect of CDSS, the CDSS's life cycle should be taken into account including the type of device, the intended use and users, and working mechanism. The device should be investigated in its natural habitat: applied to the same target individuals and in the same setting as in usual care. The complex interplay between device performance, user skills and learning curves has to be incorporated methodologically [95]. The regulatory environment, including guidance on scientific evaluation, regulations and legislation and privacy issues needs to evolve together with this emerging field of health technology.

CDSS in principle enable the physician to integrate evidence and patient information into tailored strategies for daily practice and increase guideline adherence $[6,26]$. In this review, it seems that the technical basis, prompting and the type of information provided influence the effect of the CDSS on cardiovascular risk factor improvement. Also, patient involvement in the CDSS process seems to increase the effects. Roumie et al. added patient education in a third study arm: $59.5 \%$ of the patients in this group were on target regarding their blood pressure (compared to usual care: RR 1.31 (95\%CI 1.06; 1.62)). This significant improvement could be driven by increased patient empowerment. Patient empowerment can be defined as a personal disposition (patient's control over medical strategies) and as a relational concept (collaborative patient-doctor relation) and has been shown to significantly increase the compliance to therapy [96-98]. The Lancet Commission of Hypertension also suggests patient empowerment as one of the strategies to address the global burden of hypertension in the future [99].

\section{Conclusion}

In conclusion, we did not find a clear clinical benefit from CDSS in cardiovascular risk factor levels and target attainment. Some features of CDSS seem more promising than others. However, the variability in CDSS characteristics and heterogeneity of the results - emphasizing the immaturity of this research area - limit stronger conclusions. Clinical relevance of CDSS in CVRM might additionally be sought in the improvement of shared decision making and patient empowerment.

\section{Additional files}

Additional file 1: Systematic search strategy. (DOCX $14 \mathrm{~kb}$ )

Additional file 2: Critical appraisal table. (DOCX $22 \mathrm{~kb}$ )

Additional file 3: Funnel plots. (DOCX $41 \mathrm{~kb}$ )

\section{Abbreviations}

CAD: Coronary artery disease; CDSS: Computerized decision support system; Cl: Confidence interval; CVRM: Cardiovascular risk management; EHR: Electronic health record; HbA1c: Glycated hemoglobin; LDL-c: Low-density lipoprotein cholesterol; MD: Mean difference; OR: Odds ratio; PDA: Personal device assistant; $\mathrm{RCT}$ : Randomized controlled trial; RR: Risk ratio; SBP: Systolic blood pressure

\section{Acknowledgements}

Members of the Utrecht Cardiovascular Cohort-Second Manifestations of ARTerial disease-Studygroup (UCC-SMART-Studygroup): F.W. Asselbergs and H.M. Nathoe, Department of Cardiology; G.J. de Borst, Department of Vascular Surgery; M.L. Bots and M.I. Geerlings, Department of Epidemiology; M.H. Emmelot, Department of Geriatrics; P.A. de Jong and T. Leiner, Department of Radiology; A.T. Lely, Department of Obstetrics/Gynecology; N.P. van der Kaaij, Department of Cardiothoracic Surgery; L.J. Kappelle and Y.M. Ruigrok, Department of Neurology; M.C. Verhaar, Department of Nephrology, F.L.J. Visseren (chair) and J. Westerink, Department of Vascular Medicine, University Medical Center Utrecht and Utrecht University. We gratefully thank Prof. Dr. R. Scholten for sharing his expertise in systematic reviews and critically reviewing this project and manuscript.

\section{Authors' contributions}

$K G, F A, R G, D G, F V$ and MLB contributed to the conception or design of the work. KG, FA and MLB contributed to the acquisition, analysis, or interpretation of data for the work. KG and MLB drafted the manuscript. FA, AG, DG, FV and MLB critically revised the manuscript. All gave final approval and agree to be accountable for all aspects of work ensuring integrity and accuracy.

\section{Funding}

The Utrecht Cardiovascular Cohort is partly supported by ZonMw (grant number: 80-84800-98-34001). Folkert W. Asselbergs is supported by UCL Hospitals NIHR Biomedical Research Centre.

Availability of data and materials

Not applicable, all data is extracted from published articles.

Ethics approval and consent to participate

Not applicable.

Consent for publication

Not applicable.

Competing interests

The authors declare that they have no competing interests.

\section{Author details}

${ }^{1}$ Julius Center for Health Sciences and Primary Care, University Medical Center Utrecht, University of Utrecht, Heidelberglaan 100, 3584, CX, Utrecht, the Netherlands. ${ }^{2}$ Department of Cardiology, Division Heart \& Lungs, 
University Medical Center Utrecht, University of Utrecht, Utrecht, The Netherlands. ${ }^{3}$ Institute of Cardiovascular Science, Faculty of Population Health Sciences, University College London, London, UK. ${ }^{4}$ Health Data Research UK and Institute of Health Informatics, University College London, London, UK. ${ }^{5}$ Farr Institute of Health Informatics Research and Institute of Health Informatics, University College London, London, UK. ${ }^{6}$ Department of Epidemiology, Leiden University Medical Center, Leiden, The Netherlands. ${ }^{7}$ Department of Vascular Medicine, University Medical Center Utrecht, University of Utrecht, Utrecht, The Netherlands.

\section{Received: 17 January 2019 Accepted: 20 May 2019}

Published online: 10 June 2019

\section{References}

1. Maddox TM, Albert NM, Borden WB, Curtis LH, Ferguson TB Jr, Kao DP, et al. The learning healthcare system and cardiovascular care: a scientific statement from the American Heart Association. Circulation. 2017;135(14):e826-e57.

2. Piepoli MF, Hoes AW, Agewall S, Albus C, Brotons C, Catapano AL, et al. European guidelines on cardiovascular disease prevention in clinical practice: the sixth joint task force of the European Society of Cardiology and Other Societies on Cardiovascular Disease Prevention in Clinical Practice (constituted by representatives of 10 societies and by invited experts) Developed with the special contribution of the European Association for Cardiovascular Prevention \& Rehabilitation (EACPR). Eur Heart J. 2016:37(29):2315-81.

3. Jan S, Usherwood T, Brien JA, Peiris D, Rose J, Hayman N, et al. What determines adherence to treatment in cardiovascular disease prevention? Protocol for a mixed methods preference study. BMJ open. 2011;1(2):e000372.

4. Koopman C, Vaartjes I, Heintjes EM, Spiering W, van Dis I, Herings RM, et al. Persisting gender differences and attenuating age differences in cardiovascular drug use for prevention and treatment of coronary heart disease, 1998-2010. Eur Heart J. 2013;34(41):3198-205.

5. Kotseva K, Wood D, De Bacquer D, De Backer G, Ryden L, Jennings C, et al EUROASPIRE IV: A European Society of Cardiology survey on the lifestyle, risk factor and therapeutic management of coronary patients from 24 European countries. Eur J Prev Cardiol. 2016;23(6):636-48.

6. Kawamoto K, Houlihan CA, Balas EA, Lobach DF. Improving clinical practice using clinical decision support systems: a systematic review of trials to identify features critical to success. BMJ. 2005;330(7494):765.

7. Main C, Moxham T, Wyatt JC, Kay J, Anderson R, Stein K. Computerised decision support systems in order communication for diagnostic, screening or monitoring test ordering: systematic reviews of the effects and costeffectiveness of systems. Health Technol Assess (Winchester, England). 2010;14(48):1-227. Epub 2010/11/03

8. Heselmans A, Van de Velde S, Donceel P, Aertgeerts B, Ramaekers D. Effectiveness of electronic quideline-based implementation systems in ambulatory care settings - a systematic review. Implement Sci. 2009;4:82 Epub 2010/01/01.

9. Damiani G, Pinnarelli L, Colosimo SC, Almiento R, Sicuro L, Galasso R, et al. The effectiveness of computerized clinical guidelines in the process of care: a systematic review. BMC Health Serv Res. 2010;10:2. Epub 2010/01/06.

10. Garg AX, Adhikari NK, McDonald H, Rosas-Arellano MP, Devereaux PJ, Beyene J, et al. Effects of computerized clinical decision support systems on practitioner performance and patient outcomes: a systematic review. Jama. 2005;293(10):1223-38. Epub 2005/03/10

11. Bright TJ, Wong A, Dhurjati R, Bristow E, Bastian L, Coeytaux RR, et al. Effect of clinical decision-support systems: a systematic review. Ann Intern Med. 2012;157(1):29-43 Epub 2012/07/04.

12. Delpierre C, Cuzin L, Fillaux J, Alvarez M, Massip P, Lang T. A systematic review of computer-based patient record systems and quality of care: more randomized clinical trials or a broader approach? Int J Qual Health Care. 2004;16(5):407-16. Epub 2004/09/18.

13. Bouaud J, Lamy JB. A medical informatics perspective on clinical decision support systems. Findings from the yearbook 2013 section on decision support. Yearb Med Inform. 2013;8:128-31 Epub 2013/08/27.

14. Shojania KG, Jennings A, Mayhew A, Ramsay CR, Eccles MP, Grimshaw J. The effects of on-screen, point of care computer reminders on processes and outcomes of care. Cochrane Database Syst Rev. 2009;(3):Cd001096 Epub 2009/07/10. https://doi.org/10.1002/14651858.CD001096.pub2.
15. Montani S, Bellazzi R, Quaglini S, d'Annunzio G. Meta-analysis of the effect of the use of computer-based systems on the metabolic control of patients with diabetes mellitus. Diabetes Technol Ther. 2001:3(3):347-56 Epub 2002/01/05

16. Cleveringa FG, Gorter KJ, van den Donk M, van Gijsel J, Rutten GE. Computerized decision support systems in primary care for type 2 diabetes patients only improve patients' outcomes when combined with feedback on performance and case management: a systematic review. Diabetes Technol Ther. 2013;15(2):180-92.

17. Jeffery R, Iserman E, Haynes RB, Team CSR. Can computerized clinical decision support systems improve diabetes management? A systematic review and meta-analysis. Diabet Med. 2013;30(6):739-45.

18. Ali MK, Shah S, Tandon N. Review of electronic decision-support tools for diabetes care: a viable option for low- and middle-income countries? J Diabetes Sci Technol. 2011;5(3):553-70 Epub 2011/07/05.

19. Ali SM, Giordano R, Lakhani S, Walker DM. A review of randomized controlled trials of medical record powered clinical decision support system to improve quality of diabetes care. Int J Med Inform. 2016;87:91-100.

20. Hachesu PR, Ahmadi M, Rezapoor A, Salahzadeh Z, Farahnaz S, Maroufi N. Clinical care improvement with use of health information technology focusing on evidence based medicine. Healthc Inform Res. 2012;18(3):16470 Epub 2012/11/02

21. Blum D, Raj SX, Oberholzer R, Riphagen II, Strasser F, Kaasa S, et al. Computer-Based Clinical Decision Support Systems and PatientReported Outcomes: A Systematic Review. Patient. 2015;8(5):397-409 Epub 2014/11/30.

22. Miller A, Moon B, Anders S, Walden R, Brown S, Montella D. Integrating computerized clinical decision support systems into clinical work: A metasynthesis of qualitative research. Int J Med Inform. 2015;84(12):1009-18. Epub 2015/09/24.

23. Jaspers MW, Smeulers M, Vermeulen H, Peute LW. Effects of clinical decision-support systems on practitioner performance and patient outcomes: a synthesis of high-quality systematic review findings. J Am Med Inform Assoc. 2011;18(3):327-34 Epub 2011/03/23.

24. Dowding D, Randell R, Gardner P, Fitzpatrick G, Dykes P, Favela J, et al. Dashboards for improving patient care: review of the literature. Int J Med Inform. 2015;84(2):87-100.

25. Aspry KE, Furman R, Karalis DG, Jacobson TA, Zhang AM, Liptak GS, et al. Effect of health information technology interventions on lipid management in clinical practice: a systematic review of randomized controlled trials. J Clin Lipidol. 2013;7(6):546-60.

26. Njie GJ, Proia KK, Thota AB, Finnie RK, Hopkins DP, Banks SM, et al. Clinical decision support systems and prevention: A community guide cardiovascular disease systematic review. Am J Prev Med. 2015;49(5):784-95. Epub 2015/10/20.

27. Moher D, Liberati A, Tetzlaff J, Altman DG. Preferred reporting items for systematic reviews and meta-analyses: the PRISMA statement. PLoS Med. 2009:6(7):e1000097.

28. Higgins JP, Altman DG, Gotzsche PC, Juni P, Moher D, Oxman AD, et al. The Cochrane Collaboration's tool for assessing risk of bias in randomised trials. BMJ (Clinical research ed). 2011;343:d5928.

29. Review Manager (RevMan) [Computer program]. Version 5.3. Copenhagen: The Nordic Cochrane Centre, The Cochrane Collaboration; 2014.

30. Higgins JPT, Green SE. Cochrane Handbook for Systematic Reviews of Interventions Version 5.1.0 [updated March 2011]; 2011.

31. Higgins JPT, Thompson SG, Deeks JJ, Altman D. Measuring inconsistency in meta-analyses. BMJ (Clinical research ed). 2003;327:557-60.

32. Ryan R, Group CCaCR. Heterogeneity and subgroup analyses in Cochrane Consumers and Communication Group reviews: planning the analysis at protocol stage. 2016 [03-05-2018]; Available from: http:// cccrg.cochrane.org.

33. Samal L, Linder JA, Lipsitz SR, Hicks LS. Electronic health records, clinical decision support, and blood pressure control. Am J Manag Care. 2011;17(9): 626-32 Epub 2011/09/10.

34. Shelley D, Tseng TY, Matthews AG, Wu D, Ferrari P, Cohen A, et al. Technology-driven intervention to improve hypertension outcomes in community health centers. Am J Manag Care. 2011;17(12 Spec):Sp103-10. Epub 2012/06/27

35. Maia JX, de Sousa LA, Marcolino MS, Cardoso CS, da Silva JL, Alkmim MB, et al. The Impact of a Clinical Decision Support System in Diabetes Primary Care Patients in a Developing Country. Diabetes Technol Ther. 2016;18(4): 258-63. Epub 2016/02/04. 
36. Dorr DA, Wilcox AB, Brunker CP, Burdon RE, Donnelly SM. The effect of technology-supported, multidisease care management on the mortality and hospitalization of seniors. J Am Geriatr Soc. 2008;56(12):2195-202.

37. Benner JS, Erhardt L, Flammer M, Moller RA, Rajicic N, Changela K, et al. A novel programme to evaluate and communicate 10-year risk of CHD reduces predicted risk and improves patients' modifiable risk factor profile. Int J Clin Pract. 2008;62(10):1484-98.

38. O'Connor PJ, Magid DJ, Sperl-Hillen JM, Price DW, Asche SE, Rush WA, et al. Personalised physician learning intervention to improve hypertension and lipid control: randomised trial comparing two methods of physician profiling. BMJ Qual Saf. 2014;23(12):1014-22. Epub 2014/09/18.

39. Gong Y, Zhang J. Toward a human-centered hyperlipidemia management system: the interaction between internal and external information on relational data search. J Med Syst. 2011;35(2):169-77. Epub 2010/08/13.

40. Unnikrishnan P, Kumar DK, Poosapadi Arjunan S, Kumar H, Mitchell P, Kawasaki R. Development of Health Parameter Model for Risk Prediction of CVD Using SVM. Comput Math Methods Med. 2016;2016:3016245.

41. Bosworth HB, Olsen MK, Oddone EZ. Improving blood pressure control by tailored feedback to patients and clinicians. Am Heart J. 2005;149(5):795803.

42. Bonnevie $L$, Thomsen $T$, Jorgensen $T$. The use of computerized decision support systems in preventive cardiology--principal results from the national PRECARD survey in Denmark. Eur J Cardiovasc Prev Rehabil. 2005;12(1):52-5. Epub 2005/02/11.

43. Hobbs FD, Delaney BC, Carson A, Kenkre JE. A prospective controlled trial of computerized decision support for lipid management in primary care. Fam Pract. 1996;13(2):133-7 Epub 1996/04/01.

44. Khan S, Maclean CD, Littenberg B. The effect of the Vermont Diabetes Information System on inpatient and emergency room use: results from a randomized trial. Health Outcomes Res Med. 2010;1(1):e61-e6.

45. Pignone M, Sheridan SL, Lee YZ, Kuo J, Phillips C, Mulrow C, et al. Heart to Heart: a computerized decision aid for assessment of coronary heart disease risk and the impact of risk-reduction interventions for primary prevention. Prev Cardiol. 2004;7(1):26-33 Epub 2004/03/11.

46. McDonald MV, Feldman PH, Barron-Vaya Y, Peng TR, Sridharan S, Pezzin LE. Outcomes of clinical decision support (CDS) and correlates of CDS use for home care patients with high medication regimen complexity: a randomized trial. J Eval Clin Pract. 2016;22(1):10-9. Epub 2015/05/27.

47. Mehler PS, Krantz MJ, Lundgren RA, Estacio RO, MacKenzie TD, Petralia L, et al. Bridging the quality gap in diabetic hyperlipidemia: a practice-based intervention. Am J Med. 2005;118(12):1414.

48. Dixon BE, Alzeer AH, Phillips EO, Marrero DG. Integration of Provider, Pharmacy, and Patient-Reported Data to Improve Medication Adherence for Type 2 Diabetes: A Controlled Before-After Pilot Study. JMIR Med Inform. 2016;4(1):e4

49. Peiris DP, Joshi R, Webster RJ, Groenestein P, Usherwood TP, Heeley E, et al. An electronic clinical decision support tool to assist primary care providers in cardiovascular disease risk management: development and mixed methods evaluation. J Med Internet Res. 2009;11(4):e51.

50. Love TE, Cebul RD, Einstadter D, Jain AK, Miller H, Harris CM, et al. Electronic medical record-assisted design of a cluster-randomized trial to improve diabetes care and outcomes. J Gen Intern Med. 2008; 23(4):383-91. Epub 2008/04/01.

51. Lobach DF, Hammond WE. Computerized decision support based on a clinical practice guideline improves compliance with care standards. Am J Med. 1997;102(1):89-98 Epub 1997/01/01.

52. Locatelli F, Covic A, Macdougall IC, Scherhag A, Wiecek A. Effect of computer-assisted European Best Practice Guideline implementation on adherence and target attainment: ORAMA results. J Nephrol. 2009;22(5):66274. Epub 2009/10/08.

53. Nllasena DS, Lincoln MJ. A computer-generated reminder system improves physician compliance with diabetes preventive care guidelines. AMIA. 1995;95:640-5

54. Herrin J, da Graca B, Nicewander D, Fullerton C, Aponte P, Stanek G, et al. The effectiveness of implementing an electronic health record on diabetes care and outcomes. Health Serv Res. 2012;47(4):1522-40.

55. Crosson JC, Ohman-Strickland PA, Cohen DJ, Clark EC, Crabtree BF. Typical electronic health record use in primary care practices and the quality of diabetes care. Ann Fam Med. 2012;10(3):221-7.

56. van Wyk JT, van Wijk MA, Sturkenboom MC, Mosseveld M, Moorman PW, van der Lei J. Electronic alerts versus on-demand decision support to improve dyslipidemia treatment: a cluster randomized controlled trial. Circulation. 2008;117(3):371-8. Epub 2008/01/04.

57. Tierney WM, Overhage JM, Murray MD, Harris LE, Zhou XH, Eckert GJ, et al. Effects of computerized guidelines for managing heart disease in primary care. J Gen Intern Med. 2003;18(12):967-76 Epub 2003/12/23.

58. Phillips LS, Ziemer DC, Doyle JP, Barnes CS, Kolm P, Branch WT, et al. An endocrinologist-supported intervention aimed at providers improves diabetes management in a primary care site. Diabetes Care. 2005;28(10):2352-60.

59. Frijling BD, Lobo CM, Hulscher ME, Akkermans RP, Braspenning JC, Prins A, et al. Multifaceted support to improve clinical decision making in diabetes care: a randomized controlled trial in general practice. Diabet Med. 2002;19(10):836-42. Epub 2002/10/03.

60. Lipton JA, Barendse RJ, Akkerhuis KM, Schinkel AF, Simoons ML. Evaluation of a clinical decision support system for glucose control: impact of protocol modifications on compliance and achievement of glycemic targets. Crit Pathw Cardiol. 2010;9(3):140-7. Epub 2010/08/31.

61. Augstein $P$, Vogt $L$, Kohnert KD, Heinke $P$, Salzsieder E. Translation of personalized decision support into routine diabetes care. J Diabetes Sci Technol. 2010;4(6):1532-9. Epub 2010/12/07.

62. Bertoni $A G$, Bonds $D E$, Chen $H$, Hogan $P$, Crago L, Rosenberger $E$, et al. Impact of a multifaceted intervention on cholesterol management in primary care practices: guideline adherence for heart health randomized trial. Arch Intern Med. 2009;169(7):678-86. Epub 2009/04/15.

63. Saenz A, Brito M, Moron I, Torralba A, Garcia-Sanz E, Redondo J. Development and validation of a computer application to aid the physician's decision-making process at the start of and during treatment with insulin in type 2 diabetes: a randomized and controlled trial. J Diabetes Sci Technol. 2012;6(3):581-8. Epub 2012/07/10.

64. Murray MD, Harris LE, Overhage JM, Zhou XH, Eckert GJ, Smith FE, et al. Failure of computerized treatment suggestions to improve health outcomes of outpatients with uncomplicated hypertension: results of a randomized controlled trial. Pharmacotherapy. 2004;24(3):324-37. Epub 2004/03/26.

65. Anchala R, Kaptoge S, Pant H, Di Angelantonio E, Franco OH, Prabhakaran D. Evaluation of effectiveness and cost-effectiveness of a clinical decision support system in managing hypertension in resource constrained primary health care settings: results from a cluster randomized trial. J Am Heart Assoc. 2015;4(1):e001213.

66. Hicks LS, Sequist TD, Ayanian JZ, Shaykevich S, Fairchild DG, Orav EJ, et al. Impact of computerized decision support on blood pressure management and control: a randomized controlled trial. J Gen Intern Med. 2008;23(4): 429-41. Epub 2008/04/01.

67. Montgomery AA, Fahey T, Peters TJ, Maclntosh C, Sharp DJ. Evaluation of computer based clinical decision support system and risk chart for management of hypertension in primary care: randomised controlled trial. BMJ (Clinical research ed). 2000;320(7236):686-90 Epub 2000/03/11.

68. Roumie CL, Elasy TA, Greevy R, Griffin MR, Liu X, Stone WJ, et al. Improving blood pressure control through provider education, provider alerts, and patient education: a cluster randomized trial. Ann Intern Med. 2006;145(3): 165-75 Epub 2006/08/02.

69. Eaton CB, Parker DR, Borkan J, McMurray J, Roberts MB, Lu B, et al. Translating cholesterol guidelines into primary care practice: a multimodal cluster randomized trial. Ann Fam Med. 2011;9(6):528-37 Epub 2011/11/16.

70. Gill JM, Chen YX, Glutting JJ, Diamond JJ, Lieberman MI. Impact of decision support in electronic medical records on lipid management in primary care. Popul Health Manag. 2009;12(5):221-6. Epub 2009/10/24.

71. Lester WT, Grant RW, Barnett GO, Chueh HC. Randomized controlled trial of an informatics-based intervention to increase statin prescription for secondary prevention of coronary disease. J Gen Intern Med. 2006;21(1):229 Epub 2006/01/21

72. Ali MK, Singh K, Kondal D, Devarajan R, Patel SA, Shivashankar R, et al. Effectiveness of a Multicomponent Quality Improvement Strategy to Improve Achievement of Diabetes Care Goals: A Randomized, Controlled Trial. Ann Intern Med. 2016;165(6):399-408.

73. Cleveringa FG, Gorter KJ, van den Donk M, Rutten GE. Combined task delegation, computerized decision support, and feedback improve cardiovascular risk for type 2 diabetic patients: a cluster randomized trial in primary care. Diabetes Care. 2008;31(12):2273-5. Epub 2008/09/18.

74. Glasgow RE, Nutting PA, King DE, Nelson CC, Cutter G, Gaglio B, et al. Randomized Effectiveness Trial of a Computer-Assisted Intervention to Improve Diabetes Care. Diabetes Care. 2005;28:33-9. 
75. Grant RW, Wald JS, Schnipper JL, Gandhi TK, Poon EG, Orav EJ, et al. Practice-linked online personal health records for type 2 diabetes mellitus: a randomized controlled trial. Arch Intern Med. 2008;168(16):1776-82.

76. Holbrook A, Thabane L, Keshavjee K, Dolovich L, Bernstein B, Chan D, et al. Individualized electronic decision support and reminders to improve diabetes care in the community: COMPETE II randomized trial. CMAJ. 2009;181(1-2):37-44.

77. Ilag LL, Martin CL, Tabaei BP, Isaman DJM, Burke R, Greene DA, et al. Improving Diabetes Processes of Care in Managed Care. Diabetes Care. 2003;26(10):2722-7.

78. Maclean CD, Gagnon M, Callas P, Littenberg B. The Vermont diabetes information system: a cluster randomized trial of a population based decision support system. J Gen Intern Med. 2009;24(12):1303-10.

79. Mathers N, Ng CJ, Campbell MJ, Colwell B, Brown I, Bradley A. Clinical effectiveness of a patient decision aid to improve decision quality and glycaemic control in people with diabetes making treatment choices: a cluster randomised controlled trial (PANDAs) in general practice. BMJ Open. 2012;2(6). Epub 2012/11/07. https://doi.org/10.1136/bmjopen-2012-001469.

80. Meigs JB, Cagliero E, Dubey A, Murphy-Sheehy P. A Controlled Trial of WebBased Diabetes Disease Management. Diabetes Care. 2003;26(3):750-7.

81. O'Connor PJ, Sperl-Hillen JM, Rush WA, Johnson PE, Amundson GH, Asche $\mathrm{SE}$, et al. Impact of electronic health record clinical decision support on diabetes care: a randomized trial. Ann Fam Med. 2011;9(1):12-21.

82. Ash JS, Sittig DF, Campbell E, Guappone K, Dykstra RH. An unintended consequence of CPOE implementation: shifts in power, control, and autonomy. In: AMIA Annual Symposium proceedings AMIA Symposium; 2006. p. 11-5. Epub 2007/01/24.

83. Kanstrup AM, Christiansen MB, Nohr C. Four principles for user interface design of computerised clinical decision support systems. Stud Health Technol Inform. 2011;166:65-73 Epub 2011/06/21.

84. Anchala R, Pant H, Prabhakaran D, Franco OH. Decision support system (DSS) for prevention of cardiovascular disease (CVD) among hypertensive (HTN) patients in Andhra Pradesh, India-a cluster randomised community intervention trial. BMC Public Health. 2012;12(1):393 Epub 2012/06/02.

85. Beuscart-Zephir MC, Pelayo S, Anceaux F, Meaux JJ, Degroisse M, Degoulet $P$. Impact of CPOE on doctor-nurse cooperation for the medication ordering and administration process. Int J Med Inform. 2005;74(7-8):629-41.

86. Horsky J, Kaufman DR, Patel VL. Computer-based drug ordering: evaluation of interaction with a decision-support system. Medinfo MEDINFO. 2004:1063-7.

87. Goud R, de Keizer NF, ter Riet G, Wyatt JC, Hasman A, Hellemans IM, et al. Effect of guideline based computerised decision support on decision making of multidisciplinary teams: cluster randomised trial in cardiac rehabilitation. BMJ (Clinical research ed). 2009;338:b1440 Epub 2009/04/29.

88. Holbrook A, Pullenayegum E, Thabane L, Troyan S, Foster G, Keshavjee K, et al. Shared electronic vascular risk decision support in primary care: Computerization of Medical Practices for the Enhancement of Therapeutic Effectiveness (COMPETE III) randomized trial. Arch Intern Med. 2011;171(19): 1736-44 Epub 2011/10/26

89. Mazzaglia G, Piccinni C, Filippi A, Sini G, Lapi F, Sessa E, et al. Effects of a computerized decision support system in improving pharmacological management in high-risk cardiovascular patients: A cluster-randomized open-label controlled trial. Health Inform J. 2016;22(2):232-47. Epub 2014/09/12

90. Schnipper $J$, Linder JA, Palchuk MB, Yu DT, McColgan KE, Volk LA, et al. Effects of documentation-based decision support on chronic disease management. Am J Manag Care. 2010;16(12 Suppl HIT):Sp72-81 Epub 2011/02/16

91. Sequist TD, Gandhi TK, Karson AS, Fiskio JM, Bugbee D, Sperling M, et al. A randomized trial of electronic clinical reminders to improve quality of care for diabetes and coronary artery disease. J Am Med Inform Assoc. 2005;12(4):431-7.

92. Do HP, Tran BX, Pham QL, Nguyen LH, Tran TT, Latkin CA, et al. Which eHealth interventions are most effective for smoking cessation? A systematic review. Patient Prefer Adherence. 2018;12:2064-84.

93. Anchala R, Pinto MP, Shroufi A, Chowdhury R, Sanderson J, Johnson L, et al. The role of Decision Support System (DSS) in prevention of cardiovascular disease: a systematic review and meta-analysis. PLoS One. 2012;7(10):e47064

94. Lessard L, Michalowski W, Fung-Kee-Fung M, Jones L, Grudniewicz A. Architectural frameworks: defining the structures for implementing learning health systems. Implement Sci. 2017;12(1):78.
95. KNAW. Evaluation of new technology in health care in need of guidance for relevant evidence. Amsterdam: KNAW; 2014

96. Rissel C. Empowerment: the holy grail of health promotion? Health Promot Int. 1994:9(1):39-47.

97. Nafradi L, Nakamoto K, Schulz PJ. Is patient empowerment the key to promote adherence? A systematic review of the relationship between self-efficacy, health locus of control and medication adherence. PLoS One. 2017;12(10):e0186458.

98. Sherwin S. No longer patient: Feminist ethics and health care. Philadelphia: Temple Univ Press; 1992.

99. Olsen MH, Angell SY, Asma S, Boutouyrie P, Burger D, Chirinos JA, et al. A call to action and a lifecourse strategy to address the global burden of raised blood pressure on current and future generations: the Lancet Commission on hypertension. Lancet. 2016;388(10060):2665-712.

\section{Publisher's Note}

Springer Nature remains neutral with regard to jurisdictional claims in published maps and institutional affiliations.
Ready to submit your research? Choose BMC and benefit from:

- fast, convenient online submission

- thorough peer review by experienced researchers in your field

- rapid publication on acceptance

- support for research data, including large and complex data types

- gold Open Access which fosters wider collaboration and increased citations

- maximum visibility for your research: over $100 \mathrm{M}$ website views per year

At $\mathrm{BMC}$, research is always in progress.

Learn more biomedcentral.com/submissions 